\title{
Processos erosivos superficiais: o caso da erosividade da chuva na bacia hidrográfica do rio Seridó RN/PB
}

\author{
Superficial erosive processes: the case of rain rrosivity in the hydrographic basin of river
} Seridó RN/PB

\author{
RABELO $^{1}$, D. R.; GIRÃO², I. R. F.; ARAÚJO3 ${ }^{3}$ J. C. \\ dv_rr@hotmail.com;
}

\begin{abstract}
Resumo
As chuvas são tanto a solução quanto o problema para algumas áreas do semiárido nordestino, o primeiro como solução para crises hídricas e secas severas, e no segundo como agente externo de atuação dos processos erosivos. O presente trabalho tem como objetivo calcular a erosividade da bacia hidrográfica do rio Seridó entre os anos de 1994 a 2015 para que se possa chegar ao entendimento prévio dos processos erosivos atuantes. Através da equação de Lombardi Neto e Moldenhauer foram obtidos os valores de erosividade, e estes foram interpolados através do método da krigagem. Os valores de erosividade dentro da bacia variaram entre 2.208 a 4.802 MJ.mm/(ha.h.ano), ficando assim numa classificação de baixa erosividade anual, em contrapartida, no que se refere a erosividade mensal, o índice sobe para erosividade forte. Portanto, o cálculo da erosividade é um meio para compreender a dinâmica da degradação ambiental, mais especificamente com relação ao solo, através da análise dos processos erosivos superficiais.
\end{abstract}

Palavras-chave: Erosão. Degradação ambiental. Interpolação.

\begin{abstract}
The rain are the solution and the problem for some áreas of the northeastern semiarid, the first as a solution for severe and dry crises, and the second as external agente for the erosion process. The presente work aims to calculate the erosion of the Seridó river basin between the years 1994 and 2015 so that in can reach the previous understanting of the erosive processes. Through the equation of Lambardi Neto and Moldenhauer the values of erosivity were obtained, and these were interpolated through the kriging method. The values of erosivity within the basin ranged from 2.208 to 4.802 MJ.mm/(ha.h.ano), thus being classified in a low anual erosivity, in contrast, with regard to monthly erosivity, the index rises for strong erosivity. Therefore, the calculation of erosivion. Therefore, the calculation of erosivity is a means to undestand the dynamics of environmental degradation, more specifically with respect to the soil, through the analysis of the superficial erosive processes.
\end{abstract}

Keywords: Erosion. Environmental degradation. Interpolation.

\section{INTRODUÇÃO}

A erosividade tem como principal causa à intensidade da chuva e os aspectos meteorológicos (pluviosidade) da área que é atingida. Uma das formas de se conhecer a erosividade é através do entendimento das condições climatológicas da área em que pretende pesquisar.

As condições climáticas estão impostas por diversos fatores que de acordo com o fator do posicionamento relativo à circulação global e posicionamento do globo, alguns climas são estabelecidos como a ocorrência do clima semiárido no Nordeste brasileiro. Assim como outras influências que regem a dinâmica atmosférica, a localização em latitudes baixas, no extremo norte oriental sul-americano justifica o caráter climático do semiárido. Entretanto, outros fatores como o relevo e a continentalidade também contribuem para o processo (NIMER, 1979; CONTI, 1995). 
O conhecimento das condições meteorológicas é importante pelo grau de intemperismo, escoamento hídrico e erosividade que água possui. A partir do entendimento desses fenômenos é possível analisar porque em um determinado mês do ano o poder erosivo é maior que nos outros meses.

O semiárido apresenta clima do tipo BSW'h (clima semiárido quente), segundo a classificação de koppen, que possui características marcantes de irregularidades espaço-temporal das precipitações. Estes estão em torno de $500 \mathrm{~mm}$ anuais, podendo ocorrer com primazia entre janeiro a junho. As condições climáticas são impostas por diversos fatores como o fator do posicionamento relativo à circulação global para a ocorrência do clima semiárido no Nordeste brasileiro, assim como, outras influências que regem e/ou influência a dinâmica atmosférica como é o caso do relevo. O regime pluviométrico anual possui condições heterogêneas, cujas precipitações decrescem da periferia para o interior. A estação chuvosa ocorre de janeiro a abril durante o avanço sul da ZCIT, com máxima no mês de março, sendo o recorrente na porção setentrional nordestina. A tendência é de que os demais meses permaneçam secos e o total anual não exceda $800 \mathrm{~mm}$ (NIMER, 1979; CONTI, 1995)

Quando se verificam anomalias positivas ou negativas da Temperatura da Superfície do Mar (TSM) afetam consequentemente as intensidade e duração do período chuvoso dessa região também são afetadas. Quando as águas do Atlântico Norte estão mais frias que o normal, o Sistema de Alta Pressão do Atlântico Norte e os ventos alísios de nordeste se intensificam. Se neste mesmo período o Atlântico Sul estiver mais quente que o normal, o Sistema de Alta Pressão do Atlântico Sul e os ventos alísios de sudeste enfraquecem. Este padrão favorece o deslocamento da ZCIT para posições mais ao sul da linha do Equador, e é propício à ocorrência de anos normais, chuvosos ou muito chuvosos para o setor norte do Nordeste do Brasil. (FERREIRA; MELLO, 2005, p. 16).

As variabilidades interanuais da precipitação nas regiões norte e nordeste da América do Sul têm sido associadas ao fenômeno do El Niño e La Niña (KAYANO; MOURA, 1986; MARENGO, 1992). Anomalias positivas e negativas da temperatura da superfície do mar (TSM) no Oceano Pacífico associadas ao El Niño ou La Niña produzem circulações anômalas de grande escala na atmosfera, gerando impactos significativos no clima da região da América do Sul (ACEITUNO, 1988; GRIMM et al. 2000; GRIMM, 2004). Diante disso, em anos que acontecem La Niña geralmente há aumento da pluviosidade no nordeste brasileiro, enquanto que no El Niño acontece o inverso, baixa pluviosidade no nordeste brasileiro.

Outro fenômeno climático que ocorre no Nordeste é o Vórtice Ciclônico de Altos Níveis (VCAN) que penetra na região entre os meses de novembro e março, mas com maior intensidade e frequência durante os meses de janeiro e fevereiro. O VCAN corresponde a um sistema atmosférico 
caracterizado pelo turbilhamento do ar em altos níveis da atmosfera, cobrindo extensas áreas, sendo formadas por um aglomerado de nuvens, originárias no Oceano Atlântico (FERREIRA; MELLO, 2005).

Além disso, de acordo Ferreira e Mello (2005) o último grande sistema atuante são as ondas de leste, que são ondas que se formam no campo de pressão atmosférica, na faixa tropical do globo terrestre, na área de influência dos ventos alísios, e se deslocam de leste para oeste, ou seja, desde a costa da África até o litoral leste do Brasil.

Mediante a tais dinâmicas atmosféricas, o poder erosivo das chuvas (energia cinética) é dado pela chamada erosividade, que corresponde ao fator de impacto da chuva sobre o solo. Os parâmetros de erosividade tem características de variação no tempo e no espaço, pois o mesmo depende da dinâmica atmosférica (GUERRA, 2001).

Wischmeier e Smith (1965) demonstraram que a energia cinética da chuva é determinada em função da quantidade pluviométrica ocorrida e sua intensidade. O tamanho médio das gotas de chuva aumenta com a intensidade, e a velocidade terminal das gotas em queda livre aumenta com o seu tamanho.

A região do Seridó tem sua gênese ligada as necessidades de separar a criação bovina do cultivo de cana-de-açúcar e das questões relacionadas à conquista de territórios interioranos pela política de interiorização do binômio gado-algodão. O desenvolvimento da pecuária extensiva na região do Seridó, abastecia a zona da mata destinada ao canavial, que respondia aos reclames da divisão internacional do trabalho comandada a partir da Europa.

A região só engata diretamente na divisão internacional do trabalho posteriormente com a produção de algodão, necessária ao abastecimento da indústria têxtil europeia (MACEDO, 2000). A agricultura de subsistência, visando suprir as demandas alimentares da população regional é outra marca do início da formação regional, que até hoje possui algumas marcas também. Essas foram às bases econômicas que impulsionaram às primeiras ações europeizadas, criando as primeiras próteses do meio técnico no Seridó, esboçando a forma e o conteúdo da região que estava em processo de formação.

Diante disso, áreas em que houveram degradação da cobertura vegetal ficam sujeitas aos agentes erosivos, causando assim, a degradação do solo pela perda da cobertura pedológica e das camadas mais férteis, este último atingindo diretamente aos interesses econômicos. A conservação do solo em áreas degradadas ou em estágios avançado de degradação (desertificação, para alguns autores) tendem a ficarem expostas aos impactos da erosividade da chuva.

O presente trabalho teve como objetivo analisar e interpretar o valor de erosividade para toda bacia hidrográfica do rio Seridó a partir da equação de Lombardi Neto e Moldenhauer (1992), 
que teve sua aplicabilidade em estudos realizados no Brasil, além de métodos geoestatísticos e técnicas de interpolação de dados com geoprocessamento.

\section{METODOLOGIA}

A área de estudo da presente pesquisa é a bacia hidrográfica do rio Seridó, que é a principal sub-bacia do rio Piranhas-Assu (cerca de $43,7 \mathrm{mil} \mathrm{km}^{2}$ ) e tem uma área de aproximadamente 10.000 $\mathrm{km}^{2}$. Localiza-se entre dois estados do nordeste brasileiro sendo Rio Grande do Norte e Paraíba. A região do Seridó é dividida em duas partes, são elas: Seridó Ocidental e Oriental Potiguar, e Seridó Ocidental e Oriental Paraibano.

O índice de erosividade da chuva EI30 é o produto da energia cinética da chuva $E$ com a intensidade de precipitação $I$ de 30 min ocorrido no evento pluviométrico. Correlacionando a capacidade de desagregação das partículas do solo com o transporte superficial através do salpicamento das gotas de chuva. Essas características em eventos com intensidade de até 30 min, representa o aumento do escoamento superficial à medida que a taxa de infiltração do solo diminui, relacionada às características físicas das bacias rurais (NASCIMENTO E CHAVES, 1996).

$\mathrm{O}$ fator erosividade é expresso em $\left[\mathrm{MJ} \cdot \mathrm{mm} /\left(\mathrm{ha}^{-1} \cdot \mathrm{h}^{-1} \cdot \mathrm{ano}^{-1}\right)\right]$, para se chegar ao fator $\mathrm{R}$ é necessário somar as médias dos valores mensais e anuais dos dados de chuvas obtidos pelas instituições públicas brasileiras como Agência Executiva de Gestão das Águas (AESA) e Empresa de Pesquisa Agropecuária do Rio Grande do Norte (EMPARN). Diante disso, estimar o fator R expressa pela Equação 1 recomendada de Lombardi Neto e Moldenhauer (1992):

$$
E I_{30}=68,730\left(r^{2} / P\right) * 0,841
$$

Em que:

$(E I)=$ Média mensal do índice de erosividade, em MJ.mm/(ha.h.ano);

(r) = Precipitação média mensal, em milímetros;

$(\mathrm{P})=$ Precipitação média anual, em milímetros.

Foram utilizados para o cálculo de erosividade os dados pluviométricos mensais e anuais de 30 estações pluviométricas com uma série histórica em torno de 20 anos, compreendido entre 1994 e 2015. Foram tratados dados mensais, e com os mesmos, os totais anuais pluviométricos, gerando tabela de erosividade mensal, gráficos e mapa de erosividade anual. Análise dos dados de chuva teve como base a erosividade da chuva média anual (Tabela 1). 
Tabela 1: Classe de erosividade da chuva média anual. Fonte: Carvalho (1994).

Classe de erosividade da chuva média anual

\begin{tabular}{cc}
\hline Classe de erosividade & Erosividade (R) $\mathrm{MJ} \mathrm{mm} \mathrm{ha}^{-1} \mathrm{~h}^{-1} \mathrm{ano}^{-1}$ \\
\hline 1 - Muito Baixa & $\mathrm{R}<2.452$ \\
\hline 2 - Baixa & $2.452<\mathrm{R}<4.905$ \\
\hline 3 - Média & $4.905<\mathrm{R}<7.357$ \\
\hline 4 - Alta & $7.357<\mathrm{R}<9.810$ \\
\hline 5 - Muito Alta & $\mathrm{R}>9.810$ \\
\hline
\end{tabular}

Tabela 1: Classe de erosividade da chuva média mensal. Fonte: Carvalho (1994).

Classe de erosividade da chuva média mensal

\begin{tabular}{cc}
\hline Classe de erosividade & Erosividade (R) $\mathrm{MJ} \mathrm{mm} \mathrm{ha}^{-1} \mathrm{~h}^{-1} \mathrm{ano}^{-1}$ \\
\hline 1 - Muito Baixa & $\mathrm{R}<250$ \\
\hline 2 - Baixa & $250<\mathrm{R}<500$ \\
\hline 3 - Média & $500<\mathrm{R}<750$ \\
\hline 4 - Alta & $750<\mathrm{R}<1000$ \\
\hline 5 - Muito Alta & $\mathrm{R}>1000$ \\
\hline
\end{tabular}

Para fins de mapeamento foi utilizado o método geoestatístico da krigagem, que por ser um interpolador conhecido por vários trabalhos científicos e com margens de erros pequenos comparados a outros interpoladores e métodos, é bastante utilizado.

Segundo Hartkamp et al. (1999), a principal característica desse interpolador é por ser do tipo estocástico, que fazem uso da teoria das probabilidades - são incorporados critérios estatísticos que atribuem pesos aos pontos amostrais durante a interpolação. A diferença no método de krigagem está no processo de interpolação, em que são utilizadas técnicas de geoestatística, e é expressa na Equação 2.

$$
Y(h)=\frac{1}{2 n} \sum_{i=1}^{5}(\mathrm{z}(\mathrm{Xi})-\mathrm{z}(\mathrm{Xi}+\mathrm{h})
$$

A metodologia geoestatística procura extrair, de uma aleatoriedade aparente dos dados medidos, as propriedades estruturais probabilísticas do componente regionalizado. Diante disso, é obtida uma função de correlação entre os valores situados em determinada distância e direção no espaço amostrado (LANDIM e STURARO, 2002).

Diante disso, foram interpolados através da krigagem os dados da erosividade anual dos postos pluviométricos das sedes municipais da bacia hidrográfica do rio Seridó, sendo assim, espacializando através do geoprocessamento a síntese dos eventos meteorológico anual. Os resultados mensais das erosividades foram colocados em tabelas, para que possa entender a relação das mesas com os fenômenos atmosféricos, assim como os gráficos. 


\section{RESULTADOS E DISCUSSÃO}

A partir da equação 1 foi possível determinar o valor da erosividade para 36 postos pluviométricos da bacia do Rio Seridó distribuídos pela região do Seridó Potiguar e Seridó Paraibano. Ressaltando-se que de acordo com o que os dados expostos, as chuvas variam ano para ano, sendo assim, o valor da erosividade anual é a média dos anos avaliados.

Durante o período de 20 anos, as médias anuais variaram em anos chuvosos e secos. Para efeitos de processos erosivos, a lógica é que o ano mais chuvoso tenha tido um maior gradiente de erosividade e escoamento superficial, podendo-se ocorrer erosões em áreas desprotegidas pela vegetação. Nos anos secos, apesar da pouca chuva em relação à média histórica, pode acarretar em erosões localizadas em um pico de chuva torrencial diário em um determinado período de tempo, visto que de um lugar para o outro pode ter precipitado mais.

Por se tratar de uma bacia hidrográfica de grandes dimensões (cerca de $10.000 \mathrm{~km}^{2}$ ), o valor da erosividade variou entre 2.208 a 4.802 MJ.mm/(ha/h/ano) (Figura 1). Essa variação é decorrente da distribuição espaço-temporal irregular do clima semiárido e condições geomorfológicas da bacia.



Figura 1: Mapa de Erosividade anual da bacia do Rio Seridó. Fonte: Autor, 2017. 
No mapeamento utilizando parâmetros geoestatístico foi mostrado a espacialização da chuva na área da bacia. Diante disso, a região oeste da bacia teve maior influência da erosividade na região do Seridó Potiguar. As maiores manchas de erosividade na Paraíba teve como influência a interpolação dos municípios de Serra Negra do Norte (que fica fora da área da bacia e é uma serra úmida) e o município de São Mamede (maior média pluviométrica do Seridó Paraibano).

De acordo com os gráficos, as sedes municipais do Rio Grande do Norte que ficam ao norte da bacia hidrográfica têm ocorrência de médias pluviométricas maiores que nas sedes municipais da Paraíba. Tal fenômeno pode ser entendido a partir da característica da ZCIT (principal agente climático) em seu movimento no hemisfério sul, variando sua latitude na área entre $6^{\circ}$ e $7^{\circ}$, sendo nas áreas de menor latitude as maiores precipitações.

Os valores de $\mathrm{R}$ estão expostos também nos gráficos (1 e 2) fazendo uma relação com as médias pluviométricas. Quanto maior a média pluviométrica, maior é o valor de erosividade. No entanto, há médias pluviométricas quase semelhantes e que dão valores de erosividade diferente, como é o caso dos municípios de Frei Martinho e Nova Palmeira. Ambos possuem precipitação média em torno de 454 e $457 \mathrm{~mm}$ e seus valores de erosividade são de 2.566 e 2.515 MJ.mm/(ha.h.ano), respectivamente. Diante disso, mesmo que o valor de precipitação do município de Frei Martinho tivesse sido menor (em torno de $3 \mathrm{~mm}$ a menos) em relação ao outro, o valor de erosividade foi maior. Este fato é explicado pela análise das chuvas mensalmente, sendo que na quadra chuvosa nos meses de abril e maio em Frei Martinho, a chuva foi mais intensificada que no município de Nova Palmeira (ver tabela 3).

No Seridó Paraibano, os valores erosividade variaram entre 2.402 e 4.806 MJ.mm/(ha.h.ano), sendo classificado como valor de baixo a médio para o índice de erosividade, segundo os intervalos de valores da classificação de Carvalho (Tabela 3).

No que diz respeito ao Seridó Potiguar, os valores de erosividade variaram entre 3.322 e 4.581 MJ.mm/(ha.h.ano), sendo classificado como valor médio de índice de erosividade. Grande parte dos municípios da região potiguar possui valores superiores em relação ao paraibano, justamente pela dinâmica atmosférica. 


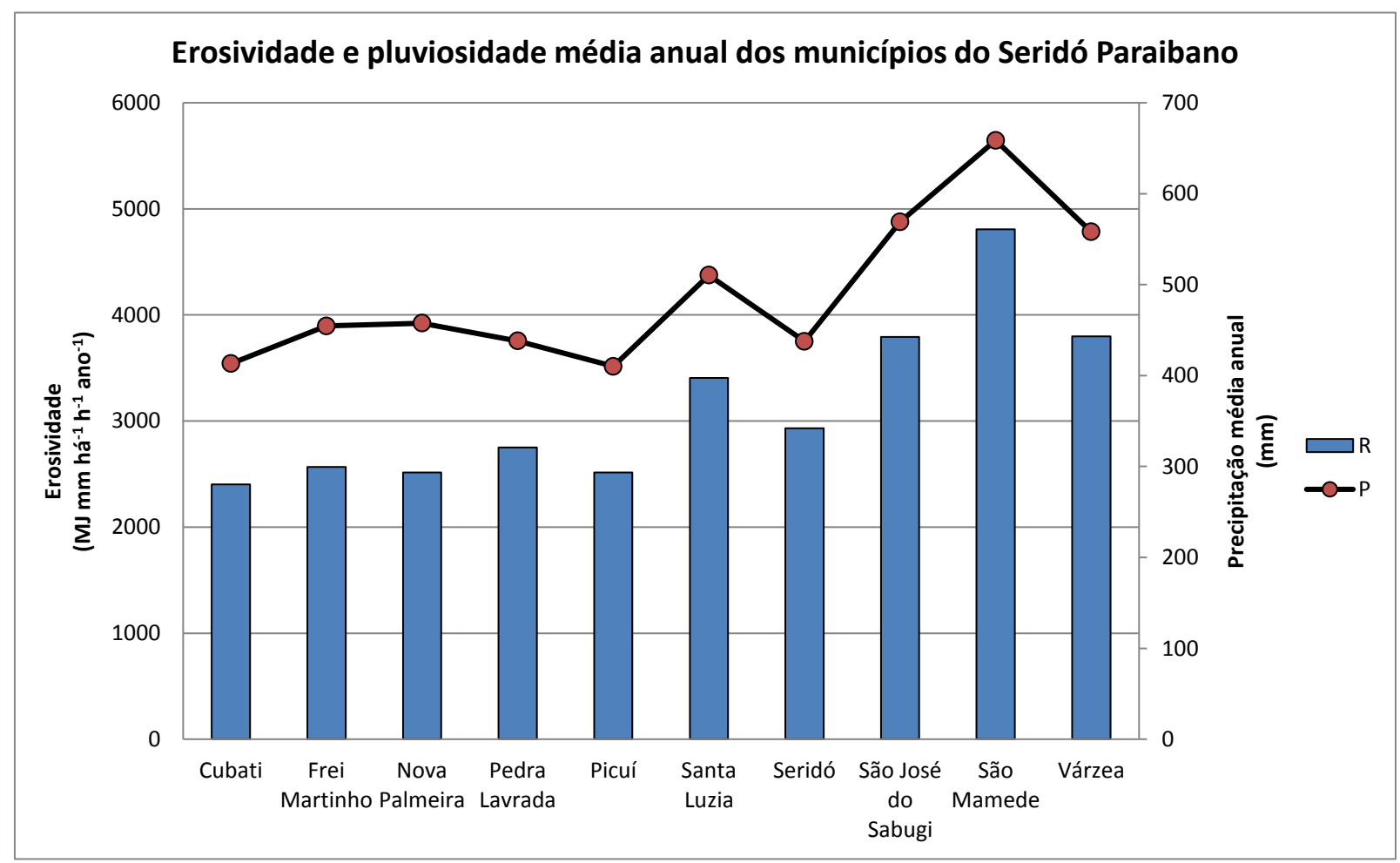

Gráfico 1: Erosividade e pluviometria dos municípios do Seridó Paraibano. Fonte: Autor, 2017.

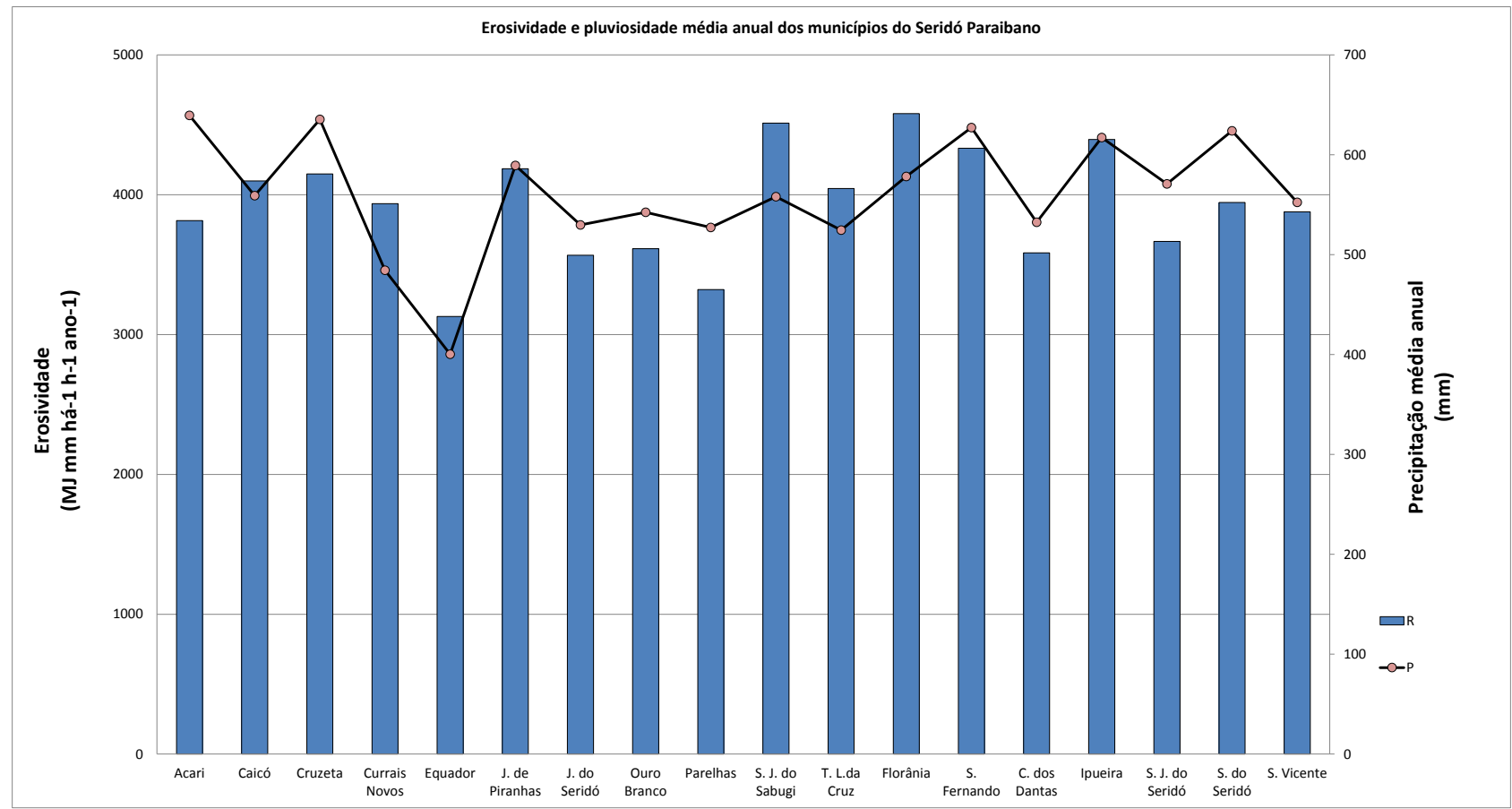

Gráfico 2: Erosividade e pluviometria dos municípios do Seridó Potiguar. Fonte: Autor, 2017.

Além da classificação anual da erosividade, existe também a classificação mensal dos dados de chuvas. A bacia hidrográfica do Seridó é classificada em grande parte como erosividade média se for considerada a classificação anual, mas na classificação mensal o cenário é diferente, de acordo com os intervalos que Carvalho (1994) propôs. 
Na tabela 3, os valores mensais de erosividade no Seridó Paraibano no período chuvoso são bem variados. Em março e abril a erosividade tem valores elevados, sendo classificada como erosividade muito alta para o primeiro e erosividade alta para o segundo. Essa erosividade alta é condicionada pela ZCIT que atua mais especificamente nesse mês na região, atrelado com picos de chuvas torrenciais. No começo do ano, mais especificamente em janeiro e fevereiro, o VCAN atua em chuvas de pré-estação chuvosa, mas dependendo da dinâmica atmosférica e a influência do deslocamento da ZCIT, são os responsáveis pelas maiores chuvas na região em determinados anos. O baixo valor em janeiro condiz com a média mensal entre os municípios da região, sendo classificado como erosividade muito baixo, mas no mês de fevereiro esse valor sobe e a classificação muda para erosividade baixa.

Os baixos valores encontrados a partir dos cálculos para os meses de junho e julho são indicativos da condição atmosférica que atua com poucas chuvas no sertão, chamada de ondas de leste, mas que na região litorânea (nordeste oriental) causam grandes precipitações nesses meses.

Tabela 3: Média de erosividade do período chuvoso na região do Seridó Paraibano. Fonte: Autor, 2017

\begin{tabular}{|c|c|c|c|c|c|c|c|}
\hline \multirow{2}{*}{ MUNICÍPIOS } & \multicolumn{7}{|c|}{ EROSIVIDADE (R) MJ mm há ${ }^{-1} h^{-1} a^{-1}$} \\
\hline & JANEIRO & FEVEREIRO & MARÇO & ABRIL & MAIO & JUNHO & JULHO \\
\hline Cubati & 162,7 & 137,9 & 627,2 & 762,2 & 387,9 & 36,4 & 14,4 \\
\hline Frei Martinho & 143,7 & 159,2 & 608,8 & 993,8 & 486,7 & 229,2 & 47,4 \\
\hline Nova Palmeira & 189,1 & 336,9 & 1076,6 & 555,7 & 164,7 & 162,3 & 26,6 \\
\hline Pedra Lavrada & 71,7 & 277,4 & 1150,0 & 758,5 & 371,8 & 105,9 & 10,9 \\
\hline Picuí & 166,6 & 154,1 & 674,3 & 1070,9 & 291,3 & 97,7 & 52,0 \\
\hline Santa Luzia & 273,2 & 440,4 & 1359,6 & 1126,1 & 158,9 & 21,3 & 5,8 \\
\hline Seridó & 156,9 & 339,3 & 273,2 & 122,6 & 134,5 & 134,5 & 27,6 \\
\hline São José do Sabugi & 361,7 & 482,3 & 1649,9 & 1031,4 & 210,0 & 41,5 & 7,8 \\
\hline São Mamede & 208,4 & 680,3 & 2457,8 & 1199,3 & 209,2 & 28,5 & 0,6 \\
\hline Várzea & 206,8 & 439,6 & 1703,6 & 1099,6 & 311,6 & 25,9 & 0,0 \\
\hline MÉDIA & 194,1 & 344,8 & 1158,1 & 872,0 & 272,7 & 88,3 & 19,3 \\
\hline
\end{tabular}

Na tabela 4 são mostrados os valores de erosividade do Seridó Potiguar, que se diferencia do paraibano tanto nas médias pluviométricas quanto na erosividade. Diferente do paraibano, no potiguar os meses de março e abril possuem uma classificação de erosividade muito alta, decorrente também da ZICT atuante. Intensificando assim, dois meses de alta atividade de chuvas torrenciais, ou seja, potencial erosivo. Nos meses de janeiro e fevereiro atuação do VCAN é maior na região, sendo classificados com valores de baixa erosividade. Nos meses de junho e julho, os valores de erosividades foram menores que na Paraíba, sendo classificada como baixa erosividade também. Esse menor valor pode ser compreendido pelo fim da quadra chuvosa da ZCIT e pela pouca 
influência das ondas de leste no sertão potiguar, possuindo empecilho para massa atmosférica também a condição geográfica do planalto da Borborema que retém mais umidade em relação à depressão sertaneja por causa da altimetria.

Tabela 4: Média de erosividade do período chuvoso na região do Seridó Potiguar. Fonte: Autor, 2017.

\begin{tabular}{|c|c|c|c|c|c|c|c|}
\hline \multirow{2}{*}{ MUNICÍPIOS } & \multicolumn{7}{|c|}{ EROSIVIDADE (R) MJ mm há ${ }^{-1} h^{-1}$ ano $^{-1}$} \\
\hline & JANEIRO & FEVEREIRO & MARÇO & ABRIL & MAIO & JUNHO & JULHO \\
\hline Acari & 255,9 & 537,0 & 1248,2 & 1035,2 & 614,1 & 112,4 & 12,0 \\
\hline Caicó & 187,8 & 827,4 & 1420,1 & 1263,7 & 342,1 & 57,8 & 0,0 \\
\hline Cruzeta & 442,3 & 618,9 & 1471,6 & 904,9 & 562,8 & 95,5 & 13,3 \\
\hline Currais Novos & 396,8 & 195,2 & 1348,3 & 1634,8 & 249,1 & 104,6 & 8,0 \\
\hline Equador & 340,6 & 391,5 & 1114,4 & 1079,3 & 128,1 & 65,5 & 9,9 \\
\hline J. de Piranhas & 531,5 & 416,2 & 1325,4 & 1508,4 & 360,3 & 39,4 & 5,5 \\
\hline J. do Seridó & 281,3 & 590,5 & 1471,7 & 948,9 & 260,4 & 14,9 & 0,0 \\
\hline Ouro Branco & 461,0 & 488,8 & 1069,0 & 1289,2 & 265,5 & 32,5 & 8,5 \\
\hline Parelhas & 249,7 & 708,7 & 1405,2 & 620,9 & 274,7 & 58,8 & 4,2 \\
\hline S. J. do Sabugi & 548,3 & 699,5 & 2137,3 & 843,8 & 259,7 & 19,5 & 3,3 \\
\hline T. L.da Cruz & 124,3 & 590,3 & 1894,3 & 1106,7 & 159,5 & 127,5 & 41,8 \\
\hline Florânia & 94,3 & 356,4 & 1686,3 & 2124,5 & 160,3 & 143,6 & 0,6 \\
\hline S. Fernando & 262,2 & 625,5 & 1325,2 & 1635,1 & 395,8 & 61,5 & 12,6 \\
\hline C. dos Dantas & 202,4 & 154,2 & 1651,6 & 912,2 & 568,5 & 95,4 & 0,0 \\
\hline Ipueira & 194,2 & 1022,4 & 2237,4 & 725,0 & 128,3 & 80,8 & 7,5 \\
\hline S. J. do Seridó & 519,4 & 450,6 & 1522,0 & 800,6 & 257,6 & 77,0 & 25,7 \\
\hline S. do Seridó & 561,0 & 780,3 & 1564,2 & 818,3 & 128,0 & 61,0 & 23,5 \\
\hline S. Vicente & 117,7 & 323,0 & 1763,0 & 1105,0 & 507,2 & 55,8 & 6,5 \\
\hline MÉDIA & 320,6 & 543,1 & 1536,4 & 1130,9 & 312,3 & 72,4 & 10,2 \\
\hline
\end{tabular}

Vários anos também foram abaixo da média histórica para região, em decorrência da fraca atuação da ZCIT ou dos VCAN, e com isso, a erosividade teve pouco potencial para os processos erosivos, se for levada em consideração que não houve tantas chuvas excepcionais diárias. Apesar disso, os processos erosivos não se dão não apenas pelo fator meteorológico, e sim por um conjunto de condições ambientais interligados.

Na Figura 02 é possível observar o processo de degradação ambiental da área, onde houveram primeiramente a retirada da cobertura vegetal para retirada de lenha e/ou para pastagem para o gado e posteriormente, atuação dos processos erosivos através da erosividade. Pode ocorrer erosão em algumas áreas devido a sazonalidade anual da chuva, somado ao processo de caducifolia da vegetação ocorrida durante a estiagem e solos desprotegidos, as chuvas concentradas num curto intervalo de tempo, resulta numa intensificação dos processos erosivos na região. 


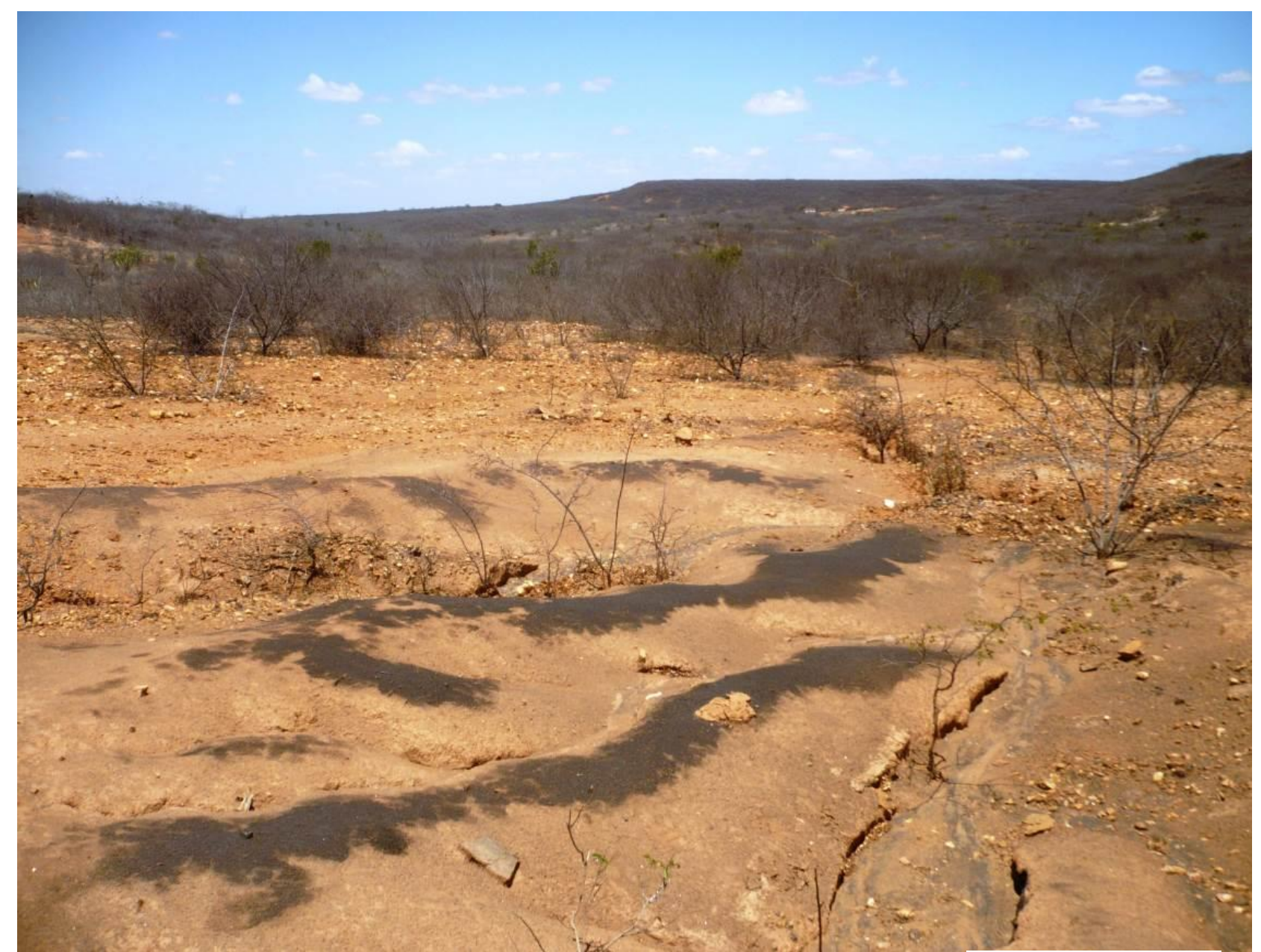

Figura 02: Erosão em sulco em uma vertente no município de Junco do Seridó. Fonte: Autores, 2017.

\section{CONSIDERAÇÕES FINAIS}

O uso do geoprocessamento auxiliou o entendimento e a espacialização desses dados e fornece meio para um planejamento hídrico e ambiental para possíveis conservação em solos degradados por erosão.

A krigagem como método estatístico que leva em consideração a posição e a relação entre os dados, foi satisfatório com bons resultados em sua distribuição que condiz com a realidade. É sempre necessário observar a variância dos dados para concluir sobre os resultados da interpolação e sua relação com a realidade. Aos fazermos a estatística dos dados coletados, tem que se ter atenção que é uma média, e como o clima semiárido ela tem características irregulares, as vezes essas médias tem que ser analisadas com cuidado, visto que a média pode mascarar o que realmente está acontecendo como uma média baixa ou alta para os padrões, levando-se a interpretações errôneas do poder erosivo da chuva.

Para se obter mais resposta ao poder erosivo da chuva são necessários mais estudos na área com modelagens e monitoramento dos dados pluviométricos. Com estudos mais avançados e um 
maior entendimento da dinâmica ambiental, a contribuição para políticas de planejamento ambiental se torna maior, e consequentemente, a redução dos danos erosivos nos solos sertanejos.

\section{REFERÊNCIAS}

ACEITUNO, P. On the functioning of the Southern Oscillation in the South American sector. Part I. surface climate. Monthly Weather Review. Pag. 505-524. 1998.

ASSAD, E. D. et al. Avaliação de métodos geoestatísticos na espacialização de índices agrometeorológicos para definir riscos climáticos. Pesquisa Agropecuária Brasileira, Brasília, v.38, n. 2, p.161-171. 2003.

CONTI, José Bueno; FURLAN, Sueli Angelo. Geoecologia: o clima, os solos e a biota. In: ROSS, Jurandyr L. (org). Geografia do Brasil. 2ed. São Paulo: Edusp, 1995.

DINIZ, M. T. M; ALMEIDA, I. C. S; SILVA, S. D. R; PEREIRA, E. M. Pedologia e análise da paisagem: interações ambientais em Junco do Seridó/PB. Caderno Prudentino de Geografia, Presidente Prudente, n.35, v.1, p.90-111, jan./jul.2013.

FERREIRA, A. G. e MELLO, N. G. da S. Principais sistemas atmosféricos atuantes sobre a região Nordeste do Brasil e a influência dos Oceanos Pacífico e Atlântico no clima da região. Revista Brasileira de Climatologia, vol. 1, nº 1, Presidente Prudente, 2005.

GRIMM, A. M.; BARROS, V. R.; DOYLE, M. E. Climate variability in southern South America associated with El Niño and La Niña events. Journal of Climate, 13: 35-58. 2000.

GRIMM, A.M. How do La Niña events disturb the summer monsoon system in Brazil? Climate Dynamics, 22: 123-138. 2004.

GUERRA, A. J. T. Processos erosivos nas encostas. In: Guerra, A. J. T \& CUNHA, S. B. (Org) Geomorfologia: uma atualização de bases e conceitos. $4^{a}$ ed. Rio de Janeiro: Bertrand Brasil, 2001.

HARTKAMP, A. D.; DE BEURS, K.; STEIN, A. \& WHITE, J. W. Interpolation Techniques for Climate Variables. NRG-GIS Series 99-01. Mexico, D. F.: CIMMYT, 34p. 1999.

KAYANO, M. T.; MOURA, A. D. O El Nino de 1982-83 e a precipitação sobre a América do Sul. Revista Brasileira de Geofísica, 4: 201-214. 1986.

LANDIM, P. M. B.; STURARO, J. R. Krigagem indicativa aplicada à elaboração de mapas probabilísticos de riscos. Rio Claro: IGCE/UNESP, Lab. Geomatemática, Texto Didático 06. 2002.

LOMBARDI NETO, F.; MOLDENHAUER, W. C. Erosividade da chuva: sua distribuição e relação com as perdas de solo em Campinas (SP). Bragantia, Campinas, pag. 189-196, 1992.

MACEDO, H. A. M. de. Quando o Sertão se descobre: os documentos pombalenses e a redescoberta da História do Seridó Colonial. O Galo - Jornal Cultural. Natal: Fundação José Augusto, ano XI, no 4, abril/maio de 2000. p. 19-22.

MARENGO, J. A. Interannual variability of surface climate in the Amazon basin. International Journal of Climatology. 12: 853-863. 1992.

MIRANDA, J. I. EMBRAPA INFORMAÇÃO TECNOLÓGICA. Fundamentos de sistemas de informações geográficas. Brasília: EMBRAPA Informação Tecnológica, 2005.- 425p.

NASCIMENTO, C. W. A. \& CHAVES, I. B. Erosividade e características da chuva correlacionadas com perdas de solo em Alagoinha - PB. Ci. Rural, 26:407-412, 1996. 
NIMER, E., 1979. Climatologia do Brasil. SUPREN/IBGE. Volume 4.

WISCHMEIER, W. H. e SMITH, D. D. Rainfall energy and its relationship to soil loss. Trans. Am. Geophys. Union, 39:285-291, 1965.

Recebido em: 29/11/2017

Aceito para publicação em: 06/05/2018 